\title{
PHYLLOLEPIS ROSSIMONTINA SP. NOV. (PLACODERMI) FROM THE UPPERMOST DEVONIAN AT RED HILL, NORTH-CENTRAL PENNSYLVANIA
}

\author{
JENNIFER A. LANE \\ Division of Paleontology (Vertebrate), American Museum of Natural History, Central Park West at 79 ${ }^{\text {th }}$ Street, New York 10024, USA. \\ jlane@amnh.org
}

ROGER J. CUFFEY

Department of Geosciences, 412 Deike Bldg., Pennsylvania State University, University Park, Pennsylvania 16802,USA. cuffey@ems.psu.edu

\begin{abstract}
Phyllolepid placoderms were heretofore known almost entirely from Greenland, western Europe, Australia, and Antarctica. Now, a suite of 31 specimens are here recognized from the United States. The locality yielding these fossils is Red Hill, a roadcut exposing late Famennian redbeds (Duncannon Member, Catskill Formation, Uppermost Devonian), east of Renovo, Clinton County, north-central Pennsylvania. One partially articulated individual, plus several isolated plates, represent Phyllolepis rossimontina sp. nov., described herein. Additional dissociated plates may represent variants of this new species, or alternatively may belong to the previously recognized species Phyllolepis concentrica, $P$. nielseni, $P$. undulata, or $P$. woodwardi. A single plate described as $P$. delicatula over a century ago from slightly older strata farther east in Pennsylvania is morphologically distinct from any of the Red Hill specimens.
\end{abstract}

Key words: Phyllolepids, placoderms, fishes, Devonian, Famennian, Pennsylvania.

\begin{abstract}
RESUMO - Até o presente, placodermos filolepídeos eram conhecidos somente na Groenlândia, oeste da Europa, Austrália e Antártica. Recentemente, um conjunto de 31 espécimens foi reconhecido na localidade de Red Hill nos Estados Unidos. Nesta localidade, os fósseis provêm de um corte de estrada, expondo redbeds" do Fameniano Superior (Membro Duncannon, Formação Catskill, parte superior do Devoniano Superior), leste de Renovo, Distrito de Clinton, central-norte de Pensilvânia. Um indivíduo parcialmente articulado, além de várias placas isoladas, representam Phyllolepis rossimontina sp.nov., aqui descrita. Outras placas adicionais, disarticuladas, podem representar variações desta nova espécie ou, alternativamente, podem pertencer a outras espécies já conhecidas, tais como: Phyllolepis concentrica, $P$. nielseni, $P$. undulata, ou $P$. woodwardi. Há mais de um século, uma única placa foi descrita como $P$. delicatula, proveniente de camadas ligeiramente mais antigas, ao leste da Pensilvânia. Phyllolepis delicatula é morfológicamente distinta dos espécimens de Red Hill.
\end{abstract}

Palavras-chave: Filolepídeos, placodermos, peixes, Devoniano, Famenniano, Pensilvania.

\section{INTRODUCTION}

The objectives of this paper are to describe a new species of phyllolepid placoderm, and to report on the suite of phyllolepid specimens, from the Late Devonian Red Hill locality in north-central Pennsylvania.These phyllolepids represent the first sizeable suite of specimens found in North America (exclusive of Greenland), and hence are of special scientific significance (Lane et al., 2001). Phyllolepids have previously been described from Greenland, Scotland, Belgium, Lithuania, Turkey, Russia, Australia, and Antarctica (Denison, 1978; Long, 1984; Ritchie, 1984).

Basal tetrapod (early amphibian) fossils, as well as other placoderm, chondrichthyan, actinopterygian, and crossopterygian fishes from Red Hill have already been described (Thomson, 1968; Daeschler et al., 1994; Daeschler, 2000a, 2000b).

\section{GEOLOGIC SETTING}

Red Hill is a long, high roadcut located along Pennsylvania Highway 120, 5.8-6.8 km east of the junction of PA Highways 120 and 144 (southbound) on the northeastern side of Renovo (Figure 1).

Rock strata exposed at this locality belong to the Duncannon Member of the deltaic Catskill Formation, of Late Famennian (Latest Devonian) age (Woodrow et al., 1995; Inners, 1987; Harper, 1999; Daeschler, 2000b; Lane, 2001). The phyllolepids come from a thin $(2 \mathrm{~m})$ zone low in the cliff in the eastern part of the roadcut (Woodrow et al., 1995). 


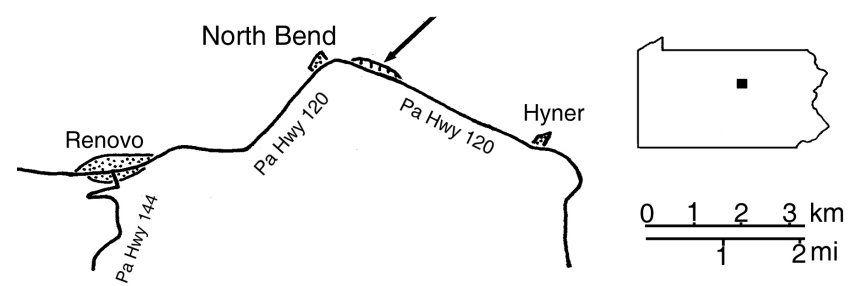

Figure 1. Location of Red Hill roadcut (arrow); base from Williamsport West $0.5^{\circ} \times 1.0^{\circ}$ topographic quadrangle (U.S. Geological Survey, 1984); inset shows location within Pennsylvania; upper scale in kilometers, lower in miles; north towards top of page.

\section{MATERIALS AND METHODS}

A total of 31 phyllolepid specimens from Red Hill were examined for the purposes of this study (Lane, 2001). These specimens are all curated at the Academy of Natural Sciences of Philadelphia (ANSP). In addition to these, the holotype of Phyllolepis delicatula Newberry, 1889, housed in the American Museum of Natural History (AMNH 6807) was examined and compared to the Red Hill material. Most of the literature comparisons focus on Stensiö's $(1934,1936,1939)$ descriptions.

The most nearly complete, partly articulated, Red Hill specimen (ANSP 20822; Figures 2-3) differs enough from previously published phyllolepid species that it warrants description as a new species of the order. Following the new species description are comments about some isolated Red Hill plates which more closely resemble other species previously described in the literature. Possible alternative interpretations are discussed where appropriate.

When confronted with a number of isolated bones, especially if representing several different plate types, it is difficult to determine which ones may represent the same species. A little variability almost always exists among such specimens, thus leading to debates about considering all as variants of only one species, versus viewing most as belonging to many different species. Not enough is yet known about phyllolepid morphology and variation to be able to diagnostically characterize every loose plate with certainty. However, some published species are known from relatively complete specimens, showing the shapes, sizes, and details of particular bone plates; some of the isolated plates can be matched with individual bones in those complete specimens, thereby suggesting tentative or possible identification with those species.

Other previously described species are known from such fragmentary remains that relating isolated Red Hill plates to them is nearly impossible. Finally, studies of placoderm intraspecific variability (especially in the abundant bothriolepids; Werdelin \& Long, 1986) may stimulate additional insight into such questions, although the Red Hill phyllolepid suite presently available is too limited for a comprehensive allometric study like theirs.
The classification of phyllolepids used here is based on Denison (1978). An alternative classification has been suggested by Long (1984:303-304), in which phyllolepids are placed in the Order Euarthrodira Gross, 1932, under the Suborder Actinolepidoidei Miles \& Young, 1977, and Infraorder Phyllolepidi Long, 1984.

Abbreviations used in text and figures. Al, anterior lateral; Avl, anterior ventrolateral; csl, central sensory line canal; Md, median dorsal; Nu, nuchal; Pn, postnasal; ppl, posterior pit line canal;Pnu, paranuchal; Pvl, posterior ventro-lateral; Sp, spinal; soc, supraorbital canal.

\section{SYSTEMATIC PALEONTOLOGY}

\author{
Class PLACODERMI M'Coy, 1848 \\ Order PHYLLOLEPIDA Stensiö, 1934 \\ Suborder PHYLLOLEPINA Stensiö, 1934 \\ Family PHYLLOLEPIDAE Woodward, 1891 \\ Genus PHYLLOLEPIS Agassiz, 1844
}

Type Species. Phyllolepis concentrica Agassiz, 1844.

Diagnosis. Stensiö (1934:34). Full generic description: Stensiö (1934:13-34; 1936:8-28).

\section{Phyllolepis rossimontina sp. nov .}

(Figures 2-4)

Holotype. ANSP 20822, a partially articulated individual preserved as part and counterpart (Figure 2-3); including nuchal, postnasal, right and left paranuchals, left spinal (Figure 4C), right and left anterior ventro-laterals, right and left posterior ventro-laterals, and possible additional small head plates (perhaps instead broken chips of the adjacent nuchal).

Referred materials. Isolated plates essentially identical to those preserved in the holotype: Nuchals (Nu): ANSP 20810, ANSP 20821 (Figure 4A-B), ANSP 21186; Anterior ventrolaterals (Avl): ANSP 20818A and B, ANSP 20826A and B (Figure 4D-E), ANSP 20827A and B, ANSP 21405; also possibly ANSP 21185; Anterior ventro-lateral (Avl) overlapped upon a posterior ventro-lateral (Pvl): ANSP 21293. Etymology. From Italian, after the locality name (Red Hill): rossi meaning red, montina meaning small mountain or hill.

Diagnosis. Phyllolepis with the following unique combination of morphologic character states: Nuchal $(\mathrm{Nu})$ plate broader than long, the length $80 \%$ of the breadth (on the holotype; varying $70-85 \%$ on additional isolated Nu plates); ornamented with numerous pits and tubercles on its anterior portion; corners "flared" or projecting where the anterolateral and posterolateral corners of the nuchal are joined; posterior margin of nuchal straight/non-curved, and posterolateral margins strongly curved. Anterior ventro-lateral plates with an exaggerated forward-extending point on the anteromedial corner as the most distinctive character; anterior margin 

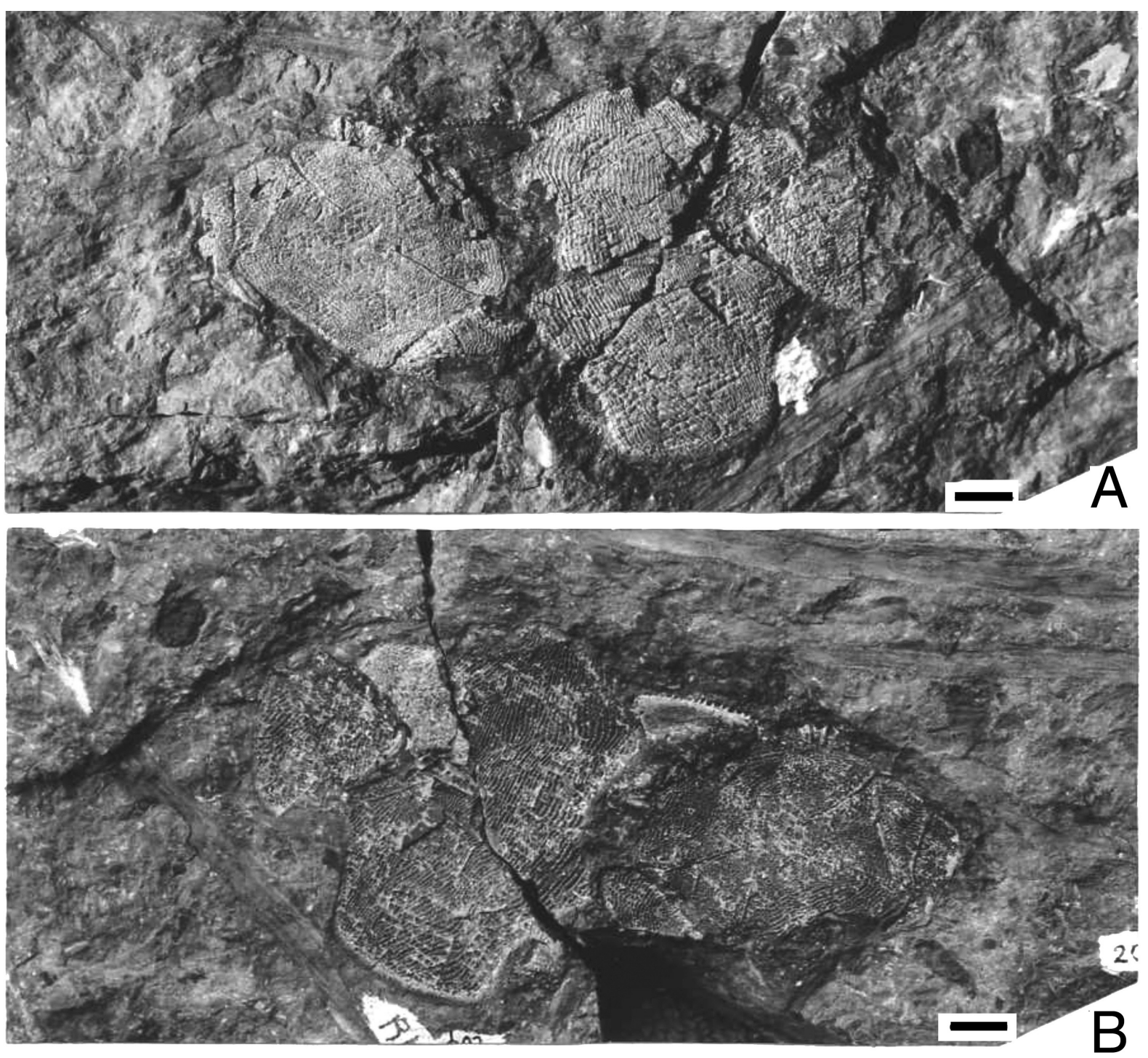

Figure 2. Phyllolepis rossimontina sp. nov., photographs of ANSP 20822 (holotype); scale bars =10 mm. A, entire specimen ("part"), showing $\mathrm{Nu}$, right and left Pnu, possible other smaller head plates, right and left Avl, left Sp, and right Pvl; B, entire counterpart, showing $\mathrm{Nu}$, right and left Pnu, Pn, right and left Avl, left Sp, and right and left Pvl.

sloping steeply posterolaterally away from the anteromedial corner, curving slightly anteriorly at the anterolateral corner; ornamentation of nearly straight, anterolaterally directed ridges on the posterior portion of the anterior ventrolateral. Posterior ventrolaterals with anterior end straight, parallel to the posteromedial margin of the anterior ventrolateral plate, slanting posterolaterally; medial margin straight; lateral margin slightly curved; ornamentation consisting of ridges.

\section{Description}

The holotype is a partially articulated individual measuring Total length $135 \times 65 \mathrm{~mm}$ (as preserved on the bedding plane, with the individual plates disoriented or disconnected); possible total body length in life approximately $320 \mathrm{~mm}$ (based on proportions shown by reconstructions in Stensiö, 1934 and Long, 1984).

Nuchals. Ornamentation on the posterior portion comprising fairly widely spaced, horizontally oriented, parallel ridges below the posterior pit line canal lines, and posterolaterally directed ridges between the central sensory line canal and posterior pit lines, with tubercles anterior to the central sensory line canal lines.

Paranuchals. Narrow and sharply pointed in the anterior portion. Lateral line canal located in the center of the plate and directed antero-laterally. Ornamentation on Pnu consisting of ridges anteriorly and tubercles posteriorly.

Postnasal. Fragmentary in this specimen, but the infraorbital canal is visible as a $\mathrm{V}$-shaped groove in the central portion of the plate, the point of the "V" almost but not quite reaching the posterior margin of the plate.

Anterior ventro-laterals. Overall appearance of roughly square, essentially equal in breadth and length. Anterior margin moderately concave, sloping away from medial margin at $60-70^{\circ}$. Lateral margin only slightly convex. Postero-lateral 

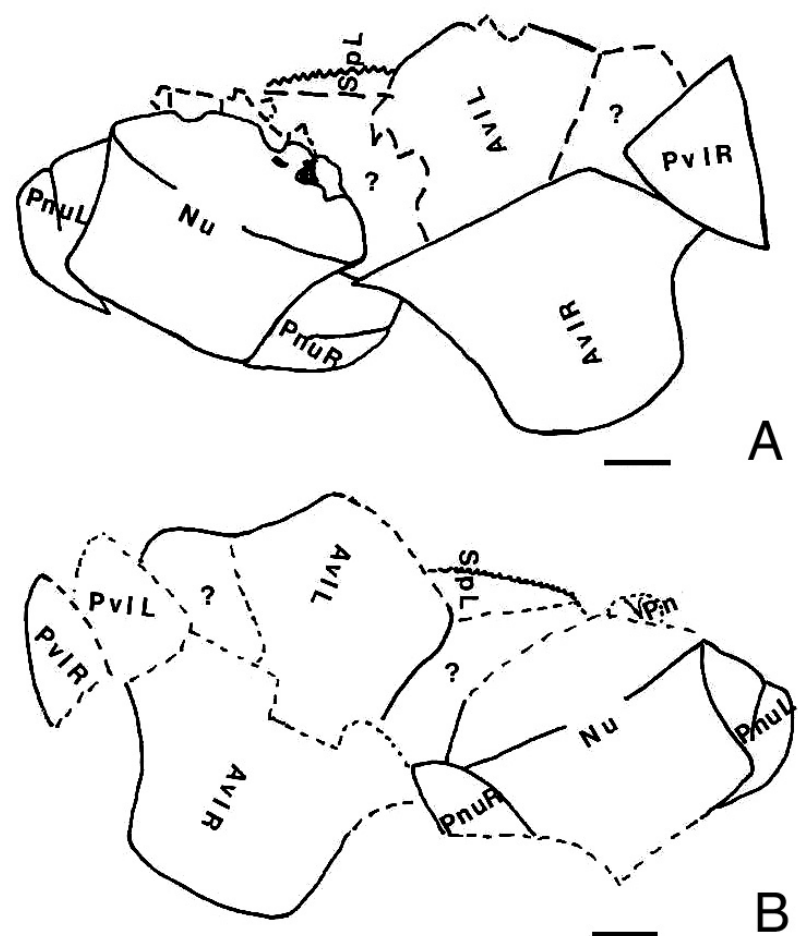

Figure 3. Phyllolepis rossimontina sp. nov., drawings of ANSP 20822 (holotype); scale bars $=10 \mathrm{~mm}$. A, entire specimen ("part"), showing $\mathrm{Nu}$, right and left Pnu, possible other smaller head plates, right and left Avl, left Sp, and right Pvl; B, entire counterpart, showing $\mathrm{Nu}$, right and left Pnu, Pn, right and left Avl, left Sp, and right and left Pvl. R \& L: right and left, respectively. Letters are oriented so that the anterior direction is toward their tops when read as a horizontal line of type.

margin moderately concave, and roughly equal in length to the postero-medial margin, which is nearly straight, slopes postero-laterally, and is $51 \%$ of the length of the medial margin (in the holotype; varying $54-68 \%$ on additional isolated plates). Angle between postero-medial and medial margins obtuse ( $129^{\circ}$ in holotype; $112-137^{\circ}$ in additional plates). Medial margin of plate straight and essentially vertical.

Posterior ventro-laterals. As in diagnosis.

Spinals. Long, thin, slightly curved; $21 \mathrm{~mm}$ in length; lateral margin ornamented with 15 small, closely spaced spines.

Comparisons to other phyllolepids. This new species can be compared and contrasted with several previously described Phyllolepis species: P. concentrica Agassiz (1844); P. konincki Stensiö (1939); P. nielseni Stensiö (1939); P. orvini Stensiö (1934); P. undulata Lohest (1888); and P. woodwardi Stensiö (1939).

Nuchal plates of this new species (Figures 2-3, 4A-B) differ from previously described Phyllolepis species in having numerous pits and tubercles on the anterior portion of the plate, and having "flared" or projecting corners where the antero-lateral and postero-lateral corners of the plate are joined.

The nuchal plate of Phyllolepis rossimontina sp. nov. is differentiated from that of $P$. woodwardi by the former's flatter posterior margin, the more pronounced curvature of the postero-lateral plate margins, the more smoothly curved projection of the antero-lateral/postero-lateral corners of the plate, and the less steeply sloping antero-lateral plate margins.

The nuchal of this new species is noticeably different from $P$. undulata in its general proportions, since in the new species the $\mathrm{Nu}$ is slightly broader than tall (height $80 \%$ of breadth as stated in diagnosis above), whereas in P. undulata, the breadth and length of the plate are roughly equal. Also, the curvature of the postero-lateral margins is more pronounced, and the posterolateral-posterior corners of the plate flare outward slightly in the new species.

The nuchal of the new species also differs from that of $P$. nielseni, in having a more pronounced curvature of the postero-lateral margins than in P. nielseni, and also in having a flatter, less convex anterior margin than P. nielseni, as well as more widely spaced ridges as ornamentation. Additionally, the nuchal in Phyllolepis rossimontina sp. nov. is more compressed than in P. nielseni, and lacks the ornamentation of concentric ridges found in that species. The nuchal plate of the new species differs from that in $P$. konincki in lacking the ornamentation of concentric ridges found in that species.

The new species has pits and tubercles on the anterior portion of the nuchal plate, whereas $P$. orvini has ridges here. The new species also differs from $P$. orvini in lacking the single central and two lateral protrusions on the anterior margin of the nuchal, and has generally much smaller nuchal plates than P. orvini.

An isolated nuchal (ANSP 21186) is assigned to Phyllolepis rossimontina sp. nov., because the general proportions and ornamentation of pits and tubercles in the anterior portion of the nuchal plate fit the characteristics of the nuchal in the holotype. However, the pattern of ornamentation posterior to the posterior pit line canal differs slightly in this specimen, consisting of wavy ridges rather than horizontal ridges arranged parallel to one another. This feature may indicate individual variation, or alternatively may indicate that this specimen represents yet another new (but as yet indeterminable) species, in addition to Phyllolepis rossimontina sp. nov.

Anterior ventro-lateral plates of the new species (Figure 2-3, 4D-E) differ from those of most other previously described phyllolepids in having an exaggerated, forward-pointing corner where the anterior and medial plate margins are joined.

Anterior ventro-laterals of the new species differ from those of $P$. undulata in that those of $P$. undulata are broader and more angular in overall appearance, with a well-defined angle where the anterior and lateral plate margins join; a straight, posterolaterally slanting lateral margin (as opposed to a curved, convex lateral margin in the new species); a sharp angle where the lateral and posterolateral plate margins join; a proportionally longer posteromedial margin; a less well-pronounced curvature to the postero-lateral plate margin; and a more posterolaterally slanting anterior margin (whereas in the new species, the anterior margin slopes upward 

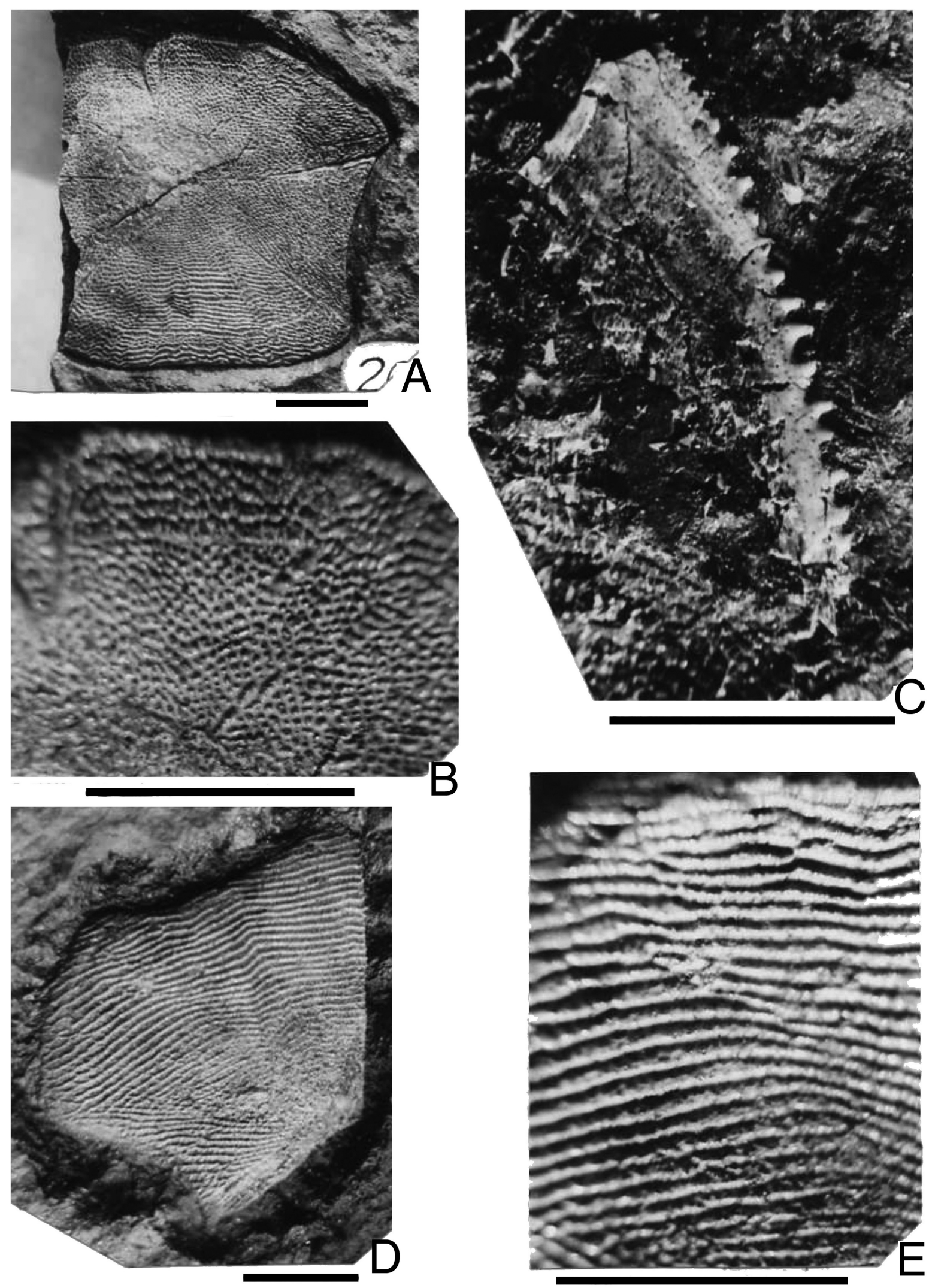

Figure 4. Phyllolepis rossimontina sp. nov., isolated plates; scale bars $=10 \mathrm{~mm}$. A-B, nuchal, ANSP 20821, overall shape (A) and pitted external ornamentation (B); C, left spinal, ANSP 20822 (holotype); D-E, right anterior ventro-lateral, ANSP 20826, overall shape (D) and corrugated external ornamentation $(\mathrm{E})$. 

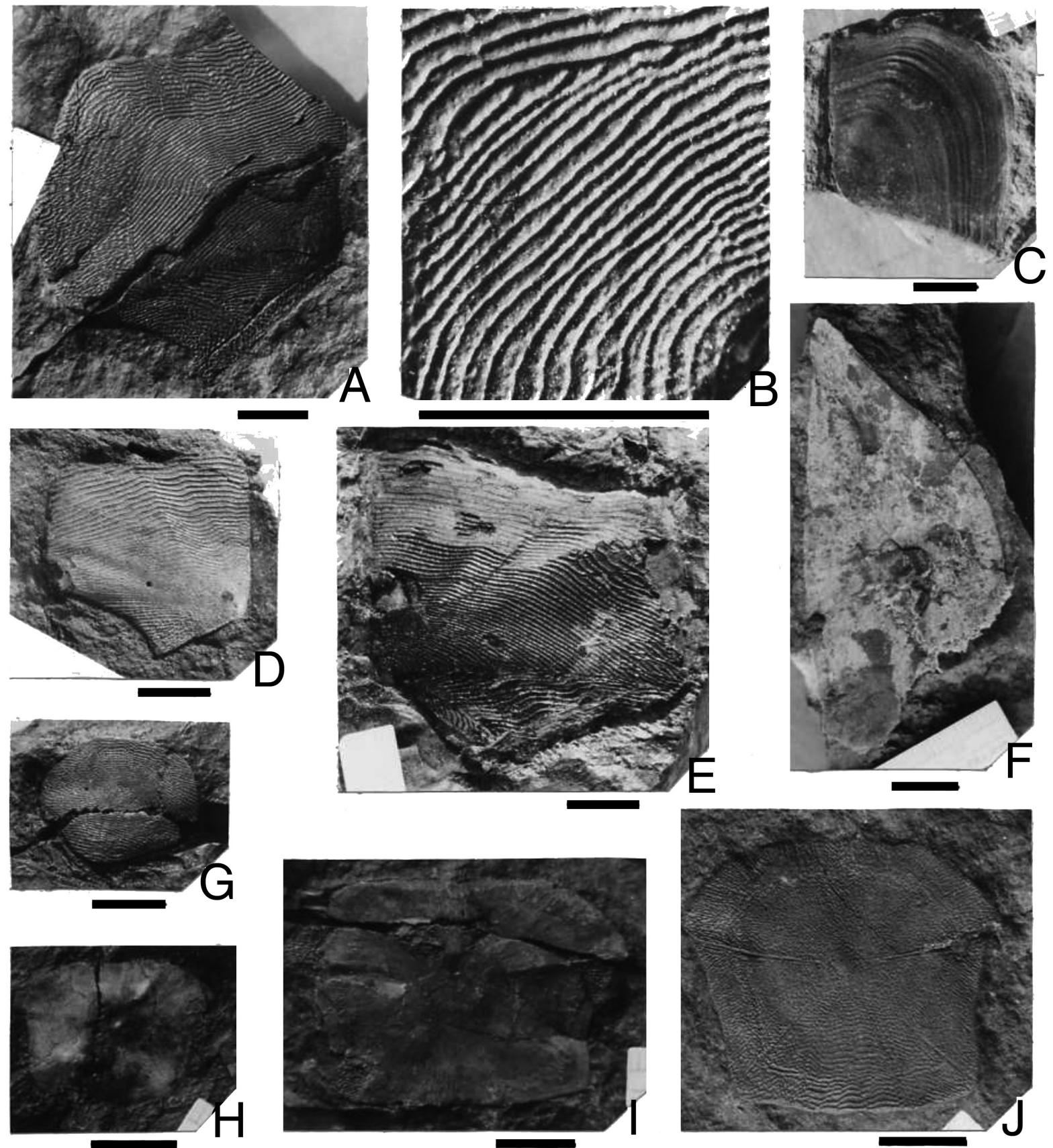

Figure 5. Isolated Red Hill plates resembling previously described Phyllolepis species. Scale bars $=10 \mathrm{~mm}$. A-B, $P$. aff. concentrica, ANSP 20813; A, right anterior ventro-lateral, external mold (A) with local concentric ornamentation within overall corrugated surface (B); C-F, $P$. aff. nielseni; C, left anterior lateral, internal mold (20820); D-E, ANSP 20824, anterior ventro-laterals, external surfaces (D, right Avl ; E. left Avl, 20823A); F, left posterior ventro-lateral, inner surface (21408); G, J, P. aff. undulata; G. median dorsal, external surface (ANSP 20817); J. nuchal, external mold (ANSP 20815B); H-I, P. aff. woodwardi, nuchals, inner surfaces (H, ANSP 20819; I, ANSP 21290A).

anterolaterally at its lateral corner).

Anterior ventrolaterals of the new species differ from those of $P$. nielseni in that anterior ventro-lateral plates of $P$. nielseni appear proportionally broader than those of the new species, and have a less convexly curved anterior margin than in the new species. Additionally, anterior ventro-lateral plates of $P$. nielseni have more steeply postero-laterally slanting lateral margins than those found in the new species.
Anterior ventero-laterals of the new species differ from those of $P$. concentrica, in lacking the ornamentation of concentrically arranged ridges parallel to the postero-lateral plate margin in $P$. concentrica. In the new species, the ornament on the postero-lateral plate margin consists of straight ridges, arranged parallel to each other, and slanting antero-laterally. Additionally, the postero-medial margin of the Avl plate is proportionally shorter in the new species (51- 
$68 \%$ of the length of the medial margin), and the angle where the medial and posteromedial plate margins join is less obtuse $\left(112-137^{\circ}\right.$ in the new species).

Anterior ventrolaterals of the new species differ from those of $P$. konincki in that those of $P$. konincki have a much more pronounced curve in the posterolateral plate margin, a more well-defined angle where the anterior and lateral plate margins are joined, and (as in P. undulata) a posterolaterally slanting lateral plate margin, as opposed to the convexly curved lateral plate margin found in the new species.

Anterior ventrolaterals of the new species differ from those of $P$. orvini in that, in $P$. orvini the anterior plate margins are quite straight and posterolaterally slanting, while in the new species, the anterior margin is convexly curved, slanting posterolaterally near the medial plate margin, and anterolaterally near its lateral margin. Additionally, anterior ventro-lateral plates in $P$. orvini have blunt anteromedial corners (unlike the pointed anteromedial plate corners in the new species), and have proportionally much longer medial and postero-medial margins.

Anterior ventrolaterals of the new species differ from those of $P$. woodwardi in that $P$. woodwardi lacks the exaggerated anteromedial plate corners found in the new species (as do all of the other previously-described phyllolepid species), and instead has blunted anteromedial plate corners supporting a unique, anterior median ventral plate (Stensiö, 1939), not seen in other phyllolepids. Additionally, in P. woodwardi, the postero-lateral margins of the Avl plate are less convexly curved than in the new species. In the specimen figured by Stensiö (1939: text-fig. 2), the lateral portions of the Avl plates of $P$. woodwardi are obscured.

The posterior ventrolaterals of the new species (Figure 23 ) differ from those of $P$. nielseni in lacking the latter's elongated plate outline, convexly curved anterior plate margin, and concavely curved posterolateral plate margin. The Pvl plates of other described phyllolepid species look similar to one another, triangular or wedge-shaped.

Spinal, paranuchal, and postnasal plates (Figures 2-3) in the new species look very similar to those of the previously described phyllolepid species. These plates do not appear to differ much among described phyllolepid species.

Recently discovered Australian phyllolepids appear significantly different in shape, size, and ornament (Long, 1984; Ritchie, 1984). Phyllolepis rossimontina sp. nov. differs from Placolepis budawangensis Ritchie, 1984, in overall shape of the nuchal plate, which in the former (like most other phyllolepids) is roughly square, rather than with a convexly curved anterior margin as in the latter. The nuchal of $P h$. rossimontina sp. nov. differs in shape from that of Austrophyllolepis ritchiei Long, 1984, especially in its anterior portion, and from that of Austrophyllolepis youngi Long, 1984, in being broader and shorter than in the Australian species. The three phyllolepid genera are quite different in their paranuchal plates; in $P h$. rossimontina sp. nov. as in other Phyllolepis species, the main lateral line canal enters the Pnu about halfway down its lateral margin, rather than at its anterior end as in Placolepis, or in the upper third of the plate as in Austrophyllolepis. Anterior ventro-lateral plates of $P h$. rossimontina sp. nov. differ in overall shape and appearance from both species of Austrophyllolepis, in having anteromedial projections and a concavely curved anterior margin, rather than this margin being straight and only slightly inclined as in Austrophyllolepis.

Finally, the Australian genera are substantially older (Givetian-Frasnian) than the Red Hill species, as well as paleogeographically some distance from the latter.

\section{ADDITIONAL PHYLLOLEPID MATERIAL AT RED HILL}

The remaining phyllolepid specimens from Red Hill can not be assigned confidently to Phyllolepis rossimontina sp. nov. because they appear visibly different from those of the new species and more closely resemble other species (particularly P. concentrica Agassiz, 1844; P. nielseni Stensiö, 1939; P. undulata Lohest 1888; and P. woodwardi Stensiö 1939), or are too fragmentary to identify with any accuracy. These additional plates are significant, however, because they suggest possibly greater species diversity at Red Hill than just the one new form. Hence, a close look at these materials (Figure 5) is necessary, as elaborated in the following paragraphs.

The specimen ANSP 20813A/B (part and counterpart, Figure $5 \mathrm{~A}-\mathrm{B}$ ) is a right anterior ventrolateral (Avl) plate showing a straight medial margin, a moderately concave anterior margin, a moderately concave posterolateral margin, and a straight, postero-laterally slanting postero-medial margin. Its lateral margin is straight to slightly convex, and oriented almost parallel to the medial margin. Ornamentation consists of widely-spaced ridges anteriorly, with small tubercles occurring centro-medially, and straight, anterolaterally slanting ridges posteriorly; a few short ridges bend around concentrically in a small area in the middle of the postero-lateral margin. Posteromedial angle is $130^{\circ}$. Those obscurely concentric ridges resemble those shown on the single Avl plate that is the neotype of Phyllolepis concentrica (Stensiö, 1939:17), although he did not explicitly say that they were "diagnostic". Also suggestive of $P$. concentrica is the posteromedial angle of 130 degrees, and explicitly mentioned by Stensiö (1939) as a feature unique to this species (in other phyllolepids, including $P$. rossimontina sp. nov., this angle is $120-125^{\circ}$ ). Stensiö (1939) indicates that the posterolateral margin is approximately the same length as the medial margin, and notes this as distinctive, but in ANSP 20813A (Figure 5A) and B the broken upper right margin makes an accurate measurement impossible. However, the medial margin appears to be longer than the postero-medial margin, which would not match $P$. concentrica. Another feature suggests the possibility that this specimen may represent 
instead a variant (possibly a more mature specimen or later growth phase) of $P$. rossimontina sp. nov., because in 20813A (Figure 5A) the interior part of the plate (slightly lighter in color than the outer rim) has an outline similar in shape to Avl plates of $P$. rossimontina sp. nov., though in $P$. rossimontina sp. nov. the posterior part of the lateral margin projects more.

ANSP 20809 and 20820 (Figure 5C) are anterior lateral (Al) plates. These plates are roughly "clam-shaped," with the medial margin long and straight, joining the anterior margin at the "umbo;" anterior margin is straight and antero-laterally directed; lateral and posterior margins are convex; smooth underside of Al plate is ornamented with concentric ridges around the outer (lateral) rim. These are similar to Stensiö's (1939:20) description and illustration of Phyllolepis nielseni in overall shape, as well as in having a slight protrusion of the posteromedial portion of the plate. However, the posterior margin of the plate is much straighter than in P. nielseni, in which this margin slants anterolaterally (Stensiö, 1939:pl. 4, fig. 1). These $\mathrm{Al}$ plates are quite different from $P$. orvini (Stensiö, 1936) in having smoothly curved, rounded posterior and lateral margins, rather than lobed or incurved margins as in P. orvini. Because no Al plates were preserved in the holotype of $P$. rossimontina sp. nov., it is not known what its Al plates look like, and it is therefore possible that these isolated $\mathrm{Al}$ plates may in fact represent this new species.

ANSP 20825 and ANSP 21406 are fragmentary plates, which may be partial Al plates resembling those of Phyllolepis nielseni just discussed, but alternatively unidentifiable to species. 20825 resembles the curved posterior part of the medial margin, or the "umbo" if the shape of the Al plate is compared to that of a clam shell (Stensiö, 1936). ANSP 21406 bears some resemblance to an Al plate in its ornamentation pattern, which all slants in the same direction. Its shape somewhat resembles that of a median dorsal (Md) plate instead, but this more likely results from breakage during fossilization, because the ornamentation pattern does not match that of a typical Md plate when well-preserved.

ANSP 20811, 20823A (Figure 5E) and B, and 20824 (Figure 5D) are anterior ventrolateral plates with an essentially straight medial margin, an anterior margin that slopes posterolaterally at a low angle ( $\left(75-80^{\circ}\right.$ with the medial margin) and is slightly concave, a nearly straight lateral margin, a moderately concave posterolateral margin, and a short straight posterolaterally slanting posteromedial margin. Posterolateral margin is somewhat longer (1.21-1.24 times longer) than the posteromedial margin. The anteromedial corner does not project noticeably cephalad (forward) as it does in the specimens of Phyllolepis rossimontina sp. nov. Ornamentation pattern consists of fairly widely-spaced, straight to wavy ridges anteriorly, changing posteriorly to very straight, parallel ridges sloping posterolaterally. The Avl plate is roughly as broad as it is long. In the roughly square shape, the long straight horizontal anterior margin, and the ornamentation pattern, these Avl plates suggest P. nielseni (Stensiö, 1939: pl. 3, fig. 3) strongly enough to imply the presence of at least a second phyllolepid species at Red Hill in addition to $P$. rossimontina sp. nov. A posteromedial angle of $120-125^{\circ}$ for these plates is also consistent with P. nielseni, although the new species likewise has a similar measurement for this angle.

One specimen, ANSP 20828A/B (part and counterpart), may represent a poorly preserved left posterior ventrolateral plate, similar to the corresponding plate in Phyllolepis nielseni (Stensiö, 1939:pl. 3, fig. 2), especially in its pattern of ornamentation. Alternatively, it may represent a broken anterior portion of a right paranuchal plate, too fragmentary to identify to species with any confidence. Another, 21408 (Figure 5F), resembles the left Pvl of P. nielseni as illustrated by Stensiö (1939, text-Figure 11), although E.B. Daeschler (2002, pers. comm.) believes it may instead be a right anteriorlateral of a groenlandaspid arthrodire.

Several Red Hill plates resemble nuchals and median dorsals of Phyllolepis undulata as figured by Lohest (1888).

ANSP 20815A and B (Figure 5J) are the part and counterpart of an isolated nuchal plate which is fairly elongate, with numerous pits and tubercles located in the anterior portion of the plate. The posterior part of this plate is ornamented with a series of horizontally arranged, parallel ridges. The supraorbital canal, central sensory line canal, and posterior pit line canal are visible on the ornamented external mold of the plate. This $\mathrm{Nu}$ appears somewhat asymmetrical or lop-sided; as a plate located on the mid-line, it would have originally been bilaterally symmetrical, hence this distortion was either diagenetic (compression during burial) or tectonic (from later Appalachian folding). However, it can still be seen that the anterior portion (maximum width $30.3 \mathrm{~mm}$ ) is only somewhat broader than its posterior margin $(20.7 \mathrm{~mm})$. This $\mathrm{Nu}$ is somewhat higher (taller, longer; 1.21 times) than broad (wide), which is approximately similar to that of Phyllolepis undulata (Stensiö, 1939, textFigure 6), although apparent breakage along the latter's anterolateral margin makes precise comparison difficult. In contrast, the Nu of $P$. rossimontina sp.nov. is 1.25 times broader (wider) than it is tall (long), exactly the opposite direction of proportions from $P$. undulata and this isolated specimen. Moreover, 20815 (Figure 5J) is similar to P. undulata (Stensiö, 1939) in having widely spaced ornamentation in the form of ridges, and further differs from $P$. rossimontina sp. nov. by lacking the more pronounced curvature of the posterolateral margins and the flared posterolateral corners found in that new species.

The specimens ANSP 20816, ANSP 20817 (Figure 5G), ANSP 21187, ANSP 21403, and probably ANSP 20812 and ANSP 21407, appear to be median dorsal plates which are short, fairly broad, and with anterolateral margins short and slanted posteroaterally. The anterior margin is long and straight; posterior margin is convexly curved; and the lateral angles are fairly acute $\left(80-85^{\circ}\right)$ and slightly rounded at the outer edges. Ornamentation consists of fairly widely spaced, concentric ridges over the entire surface of the plate. These resemble Md plates of Phyllolepis undulata (Stensiö, 1939:text-fig. 5) in overall shape, proportions, lateral-angle 
size, and ornamentation. However, as no Md plate was preserved in the partially articulated holotype of $P$. rossimontina sp. nov., and these are the only Md plates found at Red Hill, it is conceivable that these may belong to that new species instead.

ANSP 20819 (Figure 5H) and ANSP 21290A (Figure 5I) are isolated nuchal plates, broader than they are long (breadth is 1.51 times the height in $21290 \mathrm{~A}$ ). The anterior margin is flat; anterolateral margins slope posterolaterally; posterolateral margins are moderately curved; and posterior margin is slightly convex. Anterolateral margins show a rather pronounced protrusion or "flaring" outward of this plate. These specimens are preserved as smooth internal plate surfaces and internal molds, which show the ventral or visceral side of this plate, as well as a central indentation (possibly where the parasphenoid would have fit). They appear similar to Nu of Phyllolepis woodwardi (Stensiö 1939, text-figs. 2, 3), and differ from P. rossimontina sp. nov. in that $\mathrm{Nu}$ of the latter have a flatter posterior margin, a more pronounced curvature of the posterolateral plate margins, a more smoothly curved projection of the anterolateral/ posterolateral corners of the plate, and less steeply sloping anterolateral plate margins.

ANSP 20814, ANSP 21402, and ANSP 21404 are all isolated phyllolepid anterior ventrolateral plates, but so fragmentary as to be not identifiable nor comparable to species previously described.

Phyllolepis delicatula Newberry, 1889 (AMNH 6807; Newberry, 1889:97-98, pl. 19, fig.11; Stensiö, 1939:19) is known from a single isolated median dorsal plate, found further east and stratigraphically older than Red Hill, and was the only phyllolepid fragment ever recognized previously from North America (exclusive of Greenland) until now. The holotype of P. rossimontina sp. nov. does not preserve a Md plate. The few isolated Md plates from Red Hill do not resemble that of P. delicatula; the former differ from that latter by being broader and shorter, and in having a more acute lateral angle, more steeply sloping anterolateral margins, and a different pattern of ornamentation (curving, rather than straight, ridges). Whether these Red Hill Md plates are referred to $P$. undulata or to P. rossimontina sp. nov. (see above), none represents $P$. delicatula, which thus appears to be a separate Phyllolepis species.

The locality and horizon of Phyllolepis delicatula can, however, be clarified here. Newberry (1889:98) published that specimen's locality as Bradford County, Pennsylvania; it is more precisely Leroy, in southwestern Bradford County (I. Rutzky, 2001, pers. comm.). He recorded its horizon as Chemung Group, which Denison (1978) interpreted more specifically as Wellsburg Sandstone and upper Frasnian (Cooper et al., 1942). The rock containing the specimen is a greenish-gray sandstone, consistent with that stratigraphic level, and thus somewhat older than Red Hill. Detailed geologic maps show both Chemung ("Lock Haven") and Catskill Formations cropping out immediately adjacent to Leroy (Berg \& Dodge, 1981).

\section{DISCUSSION}

The main implications of the Red Hill phyllolepids are paleoecologic and biogeographic. Paleoenvironmentally, the Red Hill site formed on the inland portion of a subaerial deltaic coastal plain near the paleoequator (Barnes \& Sevon, 1996; Harper, 1999); an accessible modern analogue is the Mississippi River delta plain in central Louisiana. Local paleohabitats yielding the fish fossils were sluggish streams, quiet ponds, and water's edges, graphically reconstructed in Westenberg (1999), and whose red and green siliciclastic sediments were not altered by later soil-forming processes (Woodrow et al., 1995). None of the typical Devonian marine, coastal, or estuarine invertebrate fossils are seen in the phyllolepid deposit. Thus, these North American phyllolepids occupied fresh waters far from marine influence.

Local phyllolepid biodiversity at Red Hill is of particular paleoecologic interest. If all the resemblances noted above in discussing the additional materials are interpreted as the previously described species suggested, then as many as five phyllolepid species shared the various fresh-water subhabitats within the local Red Hill ecosystem. Such biodiversity is comparable to modern Midwestern lakes hosting several centrarchid species. Freshwaters can vary greatly in this respect, from single species up to the hundreds of cichlids in certain African lakes. In contrast, at the opposite extreme, if all the Red Hill materials represent only one species, Phyllolepis rossimontina sp. nov., then within-species variability in phyllolepids must be regarded as great, possibly further implying that previous authors have over-split these fossils. Revising all the earlier-described phyllolepid species taxonomically, however, is a task far beyond the scope of this present paper, even though speculating on possible interrelationships among those might be tempting.

The Red Hill specimens confirm extension of the range of the West European and Greenland genus Phyllolepis farther westward into the old Laurussia or "Old Red Sandstone" supercontinent (i.e. North America and Europe) than was previously known with confidence (with the exception of the single median dorsal plate named Phyllolepis delicatula by Newberry, 1889). If some of the suggested similarities discussed in the preceding section can be interpreted as certain of the previously described species, those species' ranges would be similarly extended now. As noted earlier in the new species' remarks, none of the Red Hill forms belongs to recently published Australian phyllolepid taxa (Long, 1984; Ritchie, 1984), which are substantially older (Givetian-Frasnian, rather than late Famennian).

Those geochronologic and geographic relationships suggest the possibility of origin of this order on Gondwana and subsequent migration across a circum-equatorial ocean onto Laurussia (Harper, 1999; Oliver, 2002). As noted above, Red Hill Phyllolepis rossimontina sp. nov. occurs in freshwater deposits, whereas its European relatives may have been coastal-marine forms. Depending on when the Pennsylvania 
phyllolepids' fresh-water habit evolved, getting across that ocean raises questions about which only speculation is possible in the present incomplete state of knowledge perhaps there were as-yet-undocumented intercontinental land connections (Daeschler, 2000b), maybe these fishes were euryhaline or marine-tolerant (Thomson, 1980), perhaps their life cycles were anadromous, or possibly the Red Hill phyllolepids evolved their freshwater habit after arriving in North America from marine ancestors.

Finally, future research should include detailed study of the evolutionary and biogeographic history of phyllolepids, to include phenetic and cladistic analyses of all known phyllolepid taxa, their relationship to arthrodires, and possible migratory pathways by which earlier Australian phyllolepids might have spread north into Laurussia from Gondwana.

\section{ACKNOWLEDGEMENTS}

We thank E.B. (Ted) Daeschler (ANSP) for loan of the specimens examined herein (collected under NSF grant EAR9628163) and for commenting on early versions of this manuscript; N. Douglas Rowe of the field laboratory at North Bend for providing additional fossil material, C. Frederick Mullison (ANSP) for fossil preparation; I. Rutzky (AMNH) for providing the holotype of Phyllolepis delicatula; M. Gloria P. de Carvalho for Portugese translations, and Mark E. Patzkowsky, Robert B. Eckhardt (Pennsylvania State University), and two anonymous reviewers for critically reading later versions of this manuscript. Support for this project was provided in part by the P.D. Krynine Memorial Fund of the Department of Geosciences, Pennsylvania State University. Debra Lambert finalized preparation of this manuscript.

\section{LITERATURE CITED}

Agassiz, L. 1844. Monographie des Poissons Fossiles du Vieux Grès Rouge ou Système Dèvonien (Old Red Sandstone) des Iles Brittaniques et de Russie. Neuchâtel.

Barnes, J.H. \& Sevon, W.D. 1996. The geological story of Pennsylvania. Pennsylvania Topographic and Geologic Survey Educational Series, 4:1-44.

Berg, T.M. \& Dodge, C.M. 1981. Atlas of preliminary geologic quadrangle maps of Pennsylvania. Pennsylvania Geological Survey Maps, 61:1-636.

Cooper, G.A.; Butts, C.; Caster; K.E., Chadwick; G.H.; Goldring, W.; Kindle, E.M.; Kirk, E.; Merriam, C.W.; Swartz, F.M.; Warren, P.S., Warthin, A.S. \& Willard, B. 1942. Correlation of the Devonian sedimentary formations of North America. Geological Society of America Bulletin, 53:1729-1794.

Daeschler, E.B. 2000a. An early actinopterygian fish from the Catskill Formation (Late Devonian, Famennian) in Pennsylvania, U.S.A. Academy of Natural Sciences of Philadelphia, Proceedings, 150:181-192.

Daeschler, E.B. 2000b. Early tetrapod jaws from the Late Devonian of Pennsylvania, U.S.A. Journal of Paleontology, 74(2):301-308.

Daeschler, E.B.; Shubin, N.H.; Thomson, K.S., \& Amaral, W.W. 1994. A Devonian tetrapod from North America. Science,
265:639-642.

Denison, R. 1978. Placodermi.In: H-P. Schultze (ed.) Handbook of Paleoichthyology, Gustav Fischer Verlag, pt. 2, 128 p.

Harper, J.A. 1999. Devonian. In: C.H. Shultz (ed.) The Geology of Pennsylvania. Harrisburg \& Pittsburgh, Pennsylvania Geological Survey \& Pittsburgh Geological Society, Special Publication, $1: 108-128$.

Inners, J.D. 1987. Upper Paleozoic stratigraphy along the Allegheny topographic front at the Horseshoe Curve, west-central Pennsylvania. Geological Society of America Centennial Field Guide, 5:29-36.

Lane, J.A. 2001. Phyllolepids from Red Hill (Placodermi, Devonian, Pennsylvania). Department of Geosciences, Pennsylvania State University, unpublished M.S. thesis. (UMI Dissertation Services, Ann Arbor, no. 1408508.)

Lane, J.A., Cuffey, R.J. \& Daeschler, E.B. 2001. Phyllolepid placoderms from the Catskill Formation (Latest Devonian) at Red Hill, Pennsylvania - Preliminary results. Geological Society of America Abstracts with Programs, 33(1):A-64; 33 (1):Errata:4.

Lohest, M. 1888. Recherches sur les poissons des terrains Paléozoiques de Belgique Société Géologique de Belgique, Annales, 1.15. 1887-1888.

Long, J. A. 1984. New phyllolepids from Victoria and the relationships of the group. Linnean Society of New South Wales, Proceedings, 107(3), 263-308.

Newberry, J.S. 1889. The Paleozoic fishes of North America. U.S. Geological Survey Monograph, 16:1-340.

Oliver, G.J.H. 2002. Chronology and terrane assembly, new and old controversies. In:N. H. Trewin (ed.) The Geology of Scotland, $4^{\text {th }} \mathrm{ed}$. London, The Geological Society, p. 210-211.

Ritchie, A. 1984. A new placoderm, Placolepis gen. nov. (Phyllolepidae), from the Late Devonian of New South Wales, Australia. Linnean Society of New South Wales, Proceedings, 107(3):321-353.

Stensiö, E.A. 1934. On the Placodermi of the Upper Devonian of East Greenland. Supplement to Part I. Meddelelser om Grønland, 97(1):1-58.

Stensiö, E.A. 1936. On the Placodermi of the Upper Devonian of East Greenland. I. Phyllolepida and Arthrodira. Meddelelser om Grønland, 97(2):1-52.

Stensiö, E.A. 1939. On the Placodermi of the Upper Devonian of East Greenland. Second Supplement to Part I. Meddelelser om Grønland, 97(3):1-33.

Thomson, K.S. 1968. A new Devonian fish (Crossopterygii: Rhipidistia) considered in relation to the origin of the Amphibia. Yale Peabody Museum Postilla, 124:1-13.

Thomson, K.S. 1980. The ecology of Devonian lobe-finned fishes. In: A.L.Panchen (ed.) The Terrestrial Environment and the Origin of Land Vertebrates. Academic Press, p. 187-222.

Werdelin, L. \& Long, J.A. 1986. Allometry in the placoderm Bothriolepis canadensis and its significance to antiarch evolution. Lethaia, 19:161-169.

Westenberg, K. 1999. From fins to feet. National Geographic, 195(5):114-127.

Woodrow, D.L.; Robinson, R.A.J.; Prave, A.R., Traverse, A.; Daeschler, E.B.; Rowe, N.D. \& DeLaney, N.A. 1995. Stratigraphic, sedimentologic, and temporal framework of Red Hill (Upper Devonian Catskill Formation) near Hyner, Clinton County, Pennsylvania: Site of the oldest amphibian known from North America. ANNUAL FIELD CONFERENCE OF PENNSYLVANIA GEOLOGISTS, 1995. Guidebook, 60:1-8. 